\title{
Visual Thinking: Art Students Have an Advantage in Geometric Reasoning
}

\author{
Caren M. Walker ${ }^{1}$, Ellen Winner ${ }^{2,3}$, Lois Hetland ${ }^{3,4}$, Seymour Simmons ${ }^{5}$, Lynn \\ Goldsmith $^{6}$ \\ ${ }^{1}$ University of California, Berkeley, USA; \\ ${ }^{2}$ Boston College, Boston, USA; \\ ${ }^{3}$ Harvard Graduate School of Education, Cambridge, USA; \\ ${ }^{4}$ Massachusetts College of Arts and Design, Boston, USA; \\ ${ }^{5}$ Winthrop University, Rock Hill, USA; \\ ${ }^{6}$ Education Development Center, Newton, USA. \\ Email: caren.walker@berkeley.edu \\ Received August 25 $5^{\text {th }}$, 2010; revised December $7^{\text {th }}$, 2010; accepted December $9^{\text {th }}, 2010$.
}

\begin{abstract}
We investigated whether individuals with training in the visual arts show superior performance on geometric reasoning tasks, given that both art and geometry entail visualization and mental manipulation of images. Two groups of undergraduates, one majoring in studio art, the other majoring in psychology, were given a set of geometric reasoning items designed to assess the ability to mentally manipulate geometric shapes in two- and three-dimensional space. Participants were also given a verbal intelligence test. Both training in the arts and verbal intelligence were strong predictors of geometric reasoning, but training in the arts was a significant predictor even when the effects of verbal intelligence were removed. These correlational findings lend support to the hypothesis that training in the visual arts may improve geometric reasoning via the learned cognitive skill of visualization.
\end{abstract}

Keywords: Visualization, Geometry, Spatial Reasoning, Art Education, Mathematics Education

\section{Introduction}

The ability to visualize what cannot be seen directly is considered a critical skill in mathematics and science (Cunningham, 2005). For example, when asked to reflect on his thinking, Einstein wrote that words "do not seem to play any role in my mechanism of thought.” Instead, he described the primary elements of his thinking as "certain signs and more or less clear images” (Hadamard, 1945). Kekulé reported that he discovered the circular structure of the benzene molecule after dreaming of a snake biting its own tail (Perkins, 1983). And Watson and Crick's discovery of DNA's double-helix structure involved model building and visualization (Watson, 1968). Edward Tufte's work on visualizing statistical data states, "Graphics reveal data. Indeed graphics can be more precise and revealing than conventional statistical computations" (Tufte, 2001). Virtually every STEM (Science, Technology, Engineering, and Mathematics) discipline calls upon visual or spatial thinking: chemists envision molecular structures and their interactions; geologists use field observations to envision structures that cannot be seen; engineers use visual feedback from computer models as they develop and test designs; topologists and geometers investigate mathematical relationships under various transformations.

Educational organizations in mathematics and science also emphasize the importance of visual representation and reasoning capacities (National Council of Teachers of Mathematics, 2000). For example, the Principles and Standards for School Mathematics and the Common Core Standards explicitly de- scribe visualization as a tool for problem-solving and also recognize the essential role of being able to represent and interpret mathematical ideas and problems in visual forms, including graphs, sketches, and diagrams. Despite the acknowledged importance of the role of visualization in mathematics, however, it is given relatively short shrift in many mathematics curricula (Hogan, 1993; Lappan, 1999; Goldenberg, 1996). Even geometry, a highly spatial area of mathematics, is generally taught with a strong symbolic, algebraic focus. Instead, one could argue that the dual perspectives of formal symbolism and visualization constitute complementary approaches for conceptualizing the same geometric task. Visualization may thus be applied as a tool for solving a mathematical problem in the same way that symbolic algebraic expressions can (Whiteley, 2004). It is therefore just as fundamental to educate students to engage in visual representation of geometric principles as it is to teach them to generate coherent symbolic arguments using formal algebraic notation. Support for this position comes from the work of mathematician William Thurston, famous for demonstrating the power of visual representations to communicate abstract mathematical ideas and winner of the Fields Medal in 1982. He argued that formal proofs are less appealing than the more intuitive tool of graphics to communicate abstract mathematical ideas, and he tried to develop ways to teach basic geometry through visual arguments (Hogan, 1993).

How can students develop the kinds of visualization abilities that will help them reason geometrically? We have begun to explore the possibility that the development (and exercise) of visualization skills in non-mathematical domains-for example, 
the visual arts-may support students' geometric thinking. As Gardner (2007) has argued, the visual arts are a domain that relies heavily on visual-spatial thinking. It is possible, therefore, that students who acquire training in the visual arts may be able to apply their visualization skills to support their mathematical and scientific thinking as well.

Visualization seems to be a fundamental habit of the artistic mind. Artists do not just magically "see" in their mind's eye, but deliberately and systematically analyze shape and space into familiar simple forms, construction lines, angles, and size ratios (Kozbelt, 1991). This process is essential for depicting three-dimensional objects on a two-dimensional surface. Visualization is also of value when creating three-dimensional objects, which often must be 'pictured' as a whole before they are built. An ethnographic study of intensive high school arts programs by Hetland, et al. (2007) found that 'envisioning' (visualization) is one of eight habits of mind that are taught in visual arts studio classes. Visualization (envisioning) involves the formation of images (often mental) which can then guide actions and problem solving and can even lead to problem finding (Getzles \& Csikszentmihalyi, 1975) The art teachers studied provided their students with continual practice in imagining space, line, color, and shape, regularly asking their students such questions as, "What would this look like if you extended this line?" "What is the underlying structure of this composition?" "Where would the shadow fall if the light were coming from that window?" Such questions prompt students to envision what is not there. Visual art students also study skeletal and muscular anatomy to help them envision the underlying structure of the human figure and the forces at work within various poses.

Whether based on training, innate ability, or some combination of the two, visual artists have been shown to possess superior visual-spatial capacity when compared to non-artists. Visual artists excel in mental rotation and visual memory (Casey, et al., 1990; Hermelin \& O’Connor, 1986; Rosenblatt \& Winner, 1988), visual attention and visual analysis of objects (Kozbelt \& Seeley, 2007), and form recognition (Kozbelt, 1991; Cohen \& Bennett, 1997; Mitchell, et al., 2005). In a functional MRI study, Solso (2001) examined the neural activity of artists and non-artists while they drew faces inside the scanner. Artists showed more right prefrontal activation (an area associated with the manipulation of visual forms) and less activation in the fusiform face region (an area associated with duplicating visual forms). Solso interpreted this latter finding as showing that the artist was focused less on copying the face and more on an abstract analysis of its shapes, features, and organization.

It has already been demonstrated that geometry learning fosters improvements in visualization tasks (Ben-Chaim, Lappan, \& Houang, 1988; Clements, 1997). In this study, we examined this relationship from the opposite direction, asking whether the development of visualization skills in a non-mathematical context may confer an advantage for geometric reasoning. The study presented here represents a first step in a program of research examining whether training in the visual arts transfers to geometric reasoning. The possibility of transfer is plausible because both domains rely on mental manipulation of forms in space, thereby allowing for the possibility of "near transfer" among domains that are related (Salomon \& Perkins, 1989).

\section{Methods}

\section{Participants}

A total of 36 (mostly female) college undergraduates particpated. There were 18 studio art majors (mean age $=22 ; 4$, range $=19 ; 5-27 ; 7,14$ females) and 18 psychology majors (mean age $=22 ; 10$, range $=19 ; 8-26 ; 5,17$ females). Two additional non-artists were tested but excluded because they were over two standard deviations above the mean age range (these participants were 34;4 and 41;1 years old). Both groups were seniors at the same small public university that attracts predominantly low- to mid-income students (average combined SAT score: 1045 , average GPA: 3.62 ). There were $71 \%$ White (non-Hispanic) participants, 26\% African American participants, and $<3 \%$ Hispanic, Asian, and Native-American participants. Both groups of participants had completed an average of 6.5 semesters of undergraduate work (first semester seniors).

The art majors who participated in the study had a considerable amount of art training, having taken an average of 16 undergraduate art courses. Psychology majors had taken no more than one undergraduate art course. All participants had completed approximately the same number of undergraduate math courses at the time of the study: psychology majors had completed an average of 1.7 undergraduate and 4 high school math courses, and art majors had completed an average of 1.4 undergraduate and 3.8 high school math courses.

\section{Materials \& Procedure}

With the help of a group of geometers and mathematics educators, we adapted a set of items originally developed by Callahan (1999) to create a 27-item geometric visualization/reasoning inventory. The geometric measure that we developed is not dependent upon formal geometry knowledge such as equations or definitions, but instead focuses on geometric thinking. (See Appendix A for sample geometric reasoning items used for the test. The full version of the geometric reasoning items can be found at http://www2.bc.edu/ winner/current.html). These items required participants to rely upon visual working memory and the ability to engage in various spatial transformations. Participants were not allowed to make drawings to help them solve the problems, because we wanted to assess their capacity to solve the problems using mental visualization, rather than the manipulation of external representations.

Most of the items required the ability to visualize both twoand three-dimensional space. In some items participants were asked to imagine building a shape, step-by-step, then to manipulate that shape mentally (e.g., to slice the shape into pieces; see sample item 4), and to describe the resultant shape. In other items participants were asked to mentally perform a threedimensional transformation such as a rotation on a complex shape and describe the result (see sample item 3). Finally, in some items, participants were asked to imagine a known shape (e.g., a cube, a pyramid), to perform some additional mental manipulation on that shape (e.g., to combine the shape with other shapes), and then to describe the result (see sample item 5). All items were piloted with undergraduate students and were found to be solvable, though difficult.

Participants were tested in small groups by one researcher, and the testing session lasted approximately 1.5 hours. Partici- 
pants were first asked to complete the geometric reasoning task. The 27-item task was administered in written form, but each item was read aloud as students read along silently. After the researcher reviewed each of the items aloud to the group, clarifying any confusion about wording, all participants were instructed to complete the task at their own pace and to record their answers on their individual packets. Researchers were available throughout the testing session to answer any individual questions as they arose.

To control for verbal intelligence, we administered the two verbal sections of the Kaufman Brief Intelligence Test (KBIT). The first section assesses vocabulary: participants are shown 15 pictures and asked to name each one. Items increase in difficulty (e.g., item 1 is a cash register and item 15 is a thermostat). The second section consists of 32 words, each of which has several missing letters. Participants are given a verbal clue and asked to fill in the complete word. For example, participants see BR_W_ along with the clue "a dark color;" here the correct answer is BROWN. Items increase in difficulty (e.g., item 1 was "Santa's entrance" /_ _ IM_EY [answer: CHIMNEY] and item 32 was "Due to chance or fate" / _ _ RE__I_I_Y [answer: SERENDIPITY]). Both sections began with the researcher modeling how to solve a sample problem. The KBIT items were presented on PowerPoint slides one item at a time, and participants filled in the words on their answer sheets. Following the testing session, participants completed a brief demographic questionnaire that included questions about the numbers of art and mathematics courses taken.

\section{Results}

As shown in Figure 1, performance on the geometric reasoning skills task was higher for the art majors $(M=11.46, S D=$ 4.12) than for the psychology majors $(M=8.12, S D=2.89)$, Cohen's $d=.93$. Inspection of the individual items revealed that the art majors performed better than the psychology majors on all but two of the items. To determine whether visual arts training significantly predicted geometry performance, a linear regression analysis was conducted, with the total score on the geometric reasoning task included as the dependent variable and group membership (art major vs. psychology major) and scores on the two sections of the KBIT included as independent variables.

Table 1 shows the squared bivariate correlation coefficients

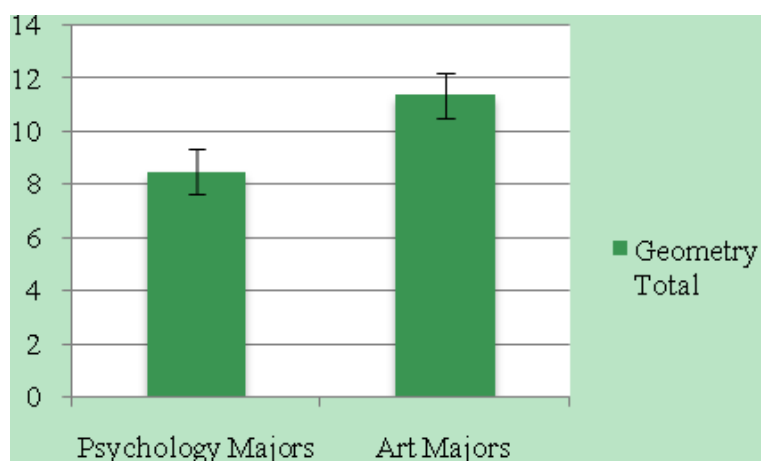

Figure 1.

Mean geometry scores for psychology majors and art majors (out of a possible score of 27).
Table 1.

Regression Analysis Showing Relationship of Arts Training and Verbal Intelligence Scores on the Geometric Reasoning Skills Task.

\begin{tabular}{cccccc}
\hline \multirow{2}{*}{ Variable } & \multicolumn{5}{c}{ Regression Analysis Results } \\
\cline { 2 - 6 } & $r^{2}$ & $t$ & $B$ & $S E_{\boldsymbol{B}}$ & Beta \\
\hline Art Training & $.402^{* *}$ & 2.310 & 2.810 & 1.219 & $.340^{*}$ \\
KBIT 1 & $.369^{*}$ & .777 & .391 & .504 & .128 \\
KBIT 2 & $2.447^{* *}$ & 2.205 & .252 & .114 & $.356^{*}$ \\
\hline
\end{tabular}

between each independent variable and geometry performance. Training in the arts and scores on the KBIT 2 (i.e., filling in missing letters to complete a word) both were strong predictors of geometry performance, by themselves and in the context of all three independent variables. Most importantly, training in the arts was a significant predictor of geometry performance (b $=.340, t(34)=2.31, p=.027)$, even when the effects of verbal intelligence (as measured by KBIT 1 and 2) were removed. Gender was not included as a variable due to the small number of male participants.

\section{Discussion}

This study provides initial evidence that individuals with college level training in visual art perform better in geometric reasoning than do individuals without such training. However, the quasi-experimental design of the research does not allow causal inferences about the direction of this relationship; we see three possible explanations for the findings. First, it is possible that training in the visual arts does have a causal effect on visual-spatial skills (which could be detected with another experimental design): visual arts training may strengthen such skills and thereby lead to improvements in geometry performance. A second possible explanation is that students self-select into the visual arts because of strong visual-spatial skills: these students may perform well in geometry as a function of their preexisting strong spatial skills, not as a function of arts training. The third explanation is that both of these possibilities are true: students with above average visual-spatial skills may opt into the visual arts and these skills may grow stronger with training. Thus, visual arts training would still lead to improved geometry performance through the mechanism of stronger spatial visualization skills. Two studies are currently underway using quasiexperimental pre-post test designs to examine these possibilities.

If transfer of visualization skill from visual arts to geometry can be demonstrated, then perhaps the visual arts will no longer be seen as a competitor for time spent in core subjects such as mathematics. In addition to their intrinsic importance, the visual arts might then be seen as an entry point for the learning of geometry or as a novel (and possibly "real world") context to deepen geometric understanding. This could especially be the case where the focus of the geometry instruction is on dynamic reasoning (e.g., Seago, Driscoll, \& Jacobs, in press) rather than the memorization and application of static rules and relationships (as is required in the generation of symbolic proofs). Furthermore, art teachers may come to see themselves as collaborators with their fellows in academic areas, intentionally focusing attention on skills like geometric reasoning, and also intentionally teaching for transfer. This collaboration may provide a 
more comprehensive education for students in both art and academics, preparing them for a future in which synthesizing knowledge from diverse domains will be essential skills (Gardner, 2007).

\section{Acknowledgements}

The authors thank Patrick Callahan for his critical role in developing the geometric reasoning task and his comments on this paper, and Paul Goldenberg and Mark Driscoll for further assistance in developing the geometry materials used in this study. We also thank Hiram Brownell and Johannah Nikula for their comments on earlier drafts of this paper. Finally, we thank Gordon David Brown and Kathy Lyon for their help in recruiting participants. This research was supported by National Science Foundation award \# DRL-0815588. Any opinions, findings and conclusions or recommendations expressed in this material are those of the authors and do not necessarily reflect the views of the National Science Foundation.

\section{References}

Battista, M. T., Clements, D. H., \& Wheatley, G. H. (1991). Using spatial imagery in geometric reasoning. Arithmetic Teacher, 39, $18-21$.

Ben-Chaim, D., Lappan, G., \& Houang, R. T. (1988). The effect of instruction on spatial visualization skills of middle school boys and girls. American Educational Research Journal, 25, 51-71.

Brieske, T. (1984). Visual thinking about rotations and reflections. The College Mathematics Journal, 15, 406-410. doi:10.2307/2686551

Callahan, P. (1999). Visualization workouts from "Geometry \& visualization: A Course for high school teachers”. unpublished notes.

Casey, M., Winner, E., Brabeck, M., \& Sullivan, K. (1990). Visual-spatial abilities in art, math, and science majors: Effects of sex, handedness, and spatial experience. In K. Gilhooly, M. Keane, R. Logie, \& G. Erdos (Eds.), Lines of thinking: Reflections on the psychology of thought. New York: Wiley.

Clements, D. H., Battista, M. T., Sarama, J., \& Swamina than, S. (1997). Development of students' spatial thinking. The Elementary School Journal, 98, 171-186. doi:10.1086/461890

Cohen, D. J., \& Bennett, S. (1997). Why can't most people draw what they see? Journal of Experimental Psychology: Human Perception and Performance, 23, 609-621. doi:10.1037/0096-1523.23.3.609

Cunningham, S. (2005). Visualization in science education. In Invention and impact: Building excellence in undergraduate science, technology, engineering, and mathematics (STEM) education (pp. 127-128). Washington, DC: AAAS Press._Gardner, H. (2007). Five Minds for the Future. Cambridge, MA: Harvard Business School Press.

Getzels, J. W., \& Csikszentmihalyi, M. (1975). From problem-solving to problem finding, In I. A. Taylor and J. W. Getzels (Eds.), Perspectives in Creativity (pp. 90-116). Chicago: Aldine.

Goldbenberg, E. P. (1996). "Habits of mind" as an organizer for the curriculum. Journal of Education. 178, 13-34.
Hadamard, J. (1945). The psychology of invention in the mathematical field. NY: Dover.

Hermelin, B., \& O'Connor, N. (1986). Spatial representations in mathematically and in artistically gifted children. British Journal of Educational Psychology, 56, 150-157.

Hetland, L., Winner, E., Veenema, S., \& Sheridan, K. (2007). Studio thinking: The real benefits of visual arts education. New York: Teachers College.

Hogan, J. (1993). The death of proof. Scientific American, 92-103.

Kozbelt, A. (1991). Artists as experts in visual cognition. Visual Cognition, 8, 705-723.

Kozbelt, A., \& Seeley, W. P. (2007). Integrating art historical, psychological, \& neuroscientific explanations of artists' advantages in drawing. PACA, 1, 80-90.

Lappan, G. (1999). Geometry: The forgotten strand. NCTM News Bulletin, $36,3$.

Mitchell, P., Ropar, D., Ackroyd, K., \& Rajendran, G. (2005). How perception impacts on drawings. Journal of Experimental Psychology: Human Perception and Per formance, 31, 996-1003. doi:10.1037/0096-1523.31.5.996

National Council of Teachers of Mathematics. (2000). Prin ciples and standards for school mathematics. Reston, VA: National Council of Teachers of Mathematics.

Perkins, D. (1983). The mind's best work. Cambridge: Harvard University Press.

Rosenblatt, E., \& Winner, E. (1988). The art of children's drawings. Journal of Aesthetic Education, 22, 1, 3-15.

Salomon, G. \& Perkins, D. N. (1989). Rocky roads to transfer: Rethinking mechanisms of a neglected phenomenon. Educational Psychologist, 24, 113-142. doi:10.1207/s15326985ep2402_1

Seago, N., Driscoll, M., \& Jacobs J. Transforming middle school geometry: designing professional development materials that support the teaching and learning of similarity. Middle Grades Research Journal, in press.

Solso, R. L. (2001). Brain activities in an expert versus a novice artist: An fMRI study. Leonardo, 34, 31-34. doi:10.1162/002409401300052479

Sutherland, R., \& Mason, J., (1993). Exploiting mental imagery with computers in mathematics education. New York: Springer-Verlag.

Tufte, E. R. (2001). The visual display of quantitative in formation (2nd ed.) CT: Graphic Press.

Watson, J. (1968). The double helix. New York: New American Library.

Winner, E., \& Casey, M. (1993). Cognitive profiles of artists. In G. Cupchik \& J. Laszlo (Eds.), Emerging visions: Contemporary approaches to the aesthetic process. London: MacDonald and Jane's Publishers.

Whiteley, W. (2004). Visualization in mathematics: Claims and questions towards a research program. Paper presented at the 10 International Congress on Mathematics Education, Copenhagen, Denmark, Cambridge, England: Cambridge University Press. 


\section{Appendix}

Appendix A. Sample Items from the Geometric Reasoning Task.

Sample Item 1. Below are pictures of "nets." You can fold them on the solid lines to make 3-dimensional forms. Circle the one(s) that can be folded into a closed form (that is, one that has no holes or openings).

Sample Item 2. How many different colors do you need to paint the faces of a cube so that no two faces that touch have the same color? Figure out the answer in your head without drawing. Describe your answer in words as best you can.

Sample Item 3. Imagine holding a small square card by the diagonal corners and spinning it around the diagonal. What shape would be carved out in the air? Figure out the answer in your head without drawing. Describe your answer in words as best you can.

Sample Item 4. Imagine a triangle that has 3 equal sides. In your mind, mark the sides of this triangle into thirds, and cut off each of the triangle's corners at the marks. Describe the shape you get. Figure out the answer in your head without drawing. Describe your answer in words as best you can.
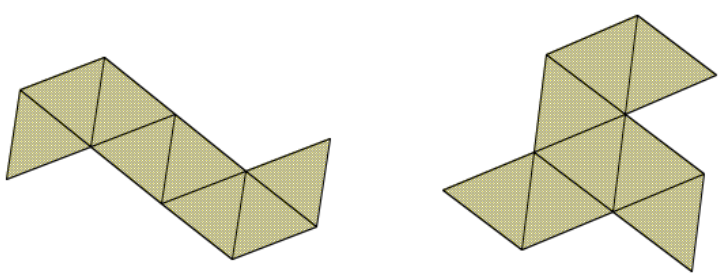

Sample Item 5. Imagine five points equally spaced around a circle. You get a regular pentagon (a shape with five equal sides) when you connect each point with the one next to it. What shape do you get if you connect every other (alternating) point? Try to figure out the answer in your head without drawing. Describe your answer as best you can.

Sample Item 6. Imagine two squares. Both have sides 1 inch long. Imagine pinning a corner of one square to the center of the other square. What is the area of the part that overlaps? Try to figure out the answer in your head, without drawing. Describe your answer in words as best you can. 